\title{
Prostaglandin D2
}

National Cancer Institute

\section{Source}

National Cancer Institute. Prostaglandin D2. NCI Thesaurus. Code C116013.

An eicosanoid that is generated by the action of prostaglandin D2 synthase on

prostaglandin H2. Prostaglandin D2 mediates vasodilation, smooth muscle contraction

and circadian rhythms. This prostanoid may also play a role in male pattern baldness. 